\title{
Anúncios publicitários na imprensa oitocentista: o empreendimento da revista $O$ Mercúrio
}

\author{
Advertisements in the 1800's press: the enterprise of the O Mercúrio magazine
}

Letícia Pedruzzi Fonseca

anúncios, belle époque, revistas ilustradas, cartazes publicitários, memória gráfica brasileira

Os anúncios ganharam destaque na imprensa brasileira no final do século XIX, especialmente nas revistas ilustradas que tinham espaço reservado ao conteúdo publicitário. Nesse contexto, tem-se a publicação da revista O Mercúrio (1898), que tinha na publicidade sua razão de existir e empregou esforços para divulgar o cartaz como mídia moderna e adequada para a comunicação dos novos produtos. Esse artigo objetiva apresentar as estratégias comerciais e os anúncios veiculados nesse periódico. Para a realização da pesquisa, foi utilizado o Conjunto metodológico para pesquisa em história do design a partir de materiais impressos (Fonseca et al., 2016) e as edições da revista O Mercúrio como objeto e fonte de pesquisa. Como resultados, tem-se a constatação sobre o pioneirismo da inclusão de anúncios em meio ao conteúdo editorial e ainda o destaque dado com a possibilidade de serem ilustrados em página inteira e impressos em duas cores. A revista tinha como ideal a produção francesa de cartazes em estilo art nouveau e se insere no contexto de propulsão da belle époque carioca com foco nesse movimento artístico e em uma comunicação que se pretendia moderna. Além disso, suas edições inovadoras e os cartazes murais que produziu e divulgou amplamente são um marco para a memória gráfica brasileira.

Advertisements, belle époque, illustrated magazines, advertising posters, Brazilian graphic memory

Advertisements gained attention in the Brazilian press towards the end of the 19th century, especially in illustrated magazines with a dedicated space to advertising content. With this as a backdrop, the $O$ Mercúrio (1898) magazine is published; having advertisement as its main purpose, the magazine employed significant effort to publicize the poster as a modern and adequate means of conveying new products. This article aims to present the commercial strategies and advertisements published in this periodical. For the research, the methodological body for research in design history from printed materials (Fonseca et al., 2016) was used as well as the O Mercúrio magazine issues as an object and source of research. It's concluded that the magazine was a pioneer in the inclusion of advertisements throughout editorial content and also the attention drawn to it due to their having an exclusive page and being printed in two colors. The magazine had its ideal in the french production of art noveau-style posters and found itself published in the midst of the rise of Rio de Janeiro's belle époque, focused on this artistic movement and in a communication style that strived for modernity. Moreover, its innovative issues and the two mural posters it developed and publicized widely are a milestone in the Brazilian graphic memory.

Anais do $10^{\circ} \mathrm{CIDI}$ e $10^{\circ} \mathrm{CONGIC}$

Kelli C.A.S. Smythe, Rafael de Castro Andrade (orgs.)

Sociedade Brasileira de Design da Informação - SBDI

Curitiba | Brasil | 2021
Proceedings of the $10^{\text {th }} \mathrm{CIDI}$ and $10^{\text {th }}$ CONGIC

Kelli C.A.S. Smythe, Rafael de Castro Andrade (orgs.)

Sociedade Brasileira de Design da Informação - SBDI Curitiba | Brazil | 2021 


\section{Introdução}

Os anúncios publicitários se destacaram na imprensa brasileira no final do século XIX e a revista se sobressaiu como suporte desse novo produto moderno. Segundo Süssekind (1987), o período da belle époque brasileira proporcionou uma significativa alteração nos comportamentos e na percepção dos que passaram a conviver cotidianamente com os novos aparelhos da vida moderna. Dentre os exemplos que a autora cita, estão as primeiras projeções do cinematógrafo, em 1896, e o projeto de veiculação sistemática de propaganda ilustrada em O Mercúrio.

O confronto, a discussão e a assimilação de tantas novidades em um curto período foram mediadas pelas revistas ilustradas, tendo em vista que o mote das crônicas textuais e imagéticas eram sempre os acontecimentos do momento, dos costumes. A revista O Mercúrio é exemplar dessa afirmação, pois foi criada por um grupo importante de literatos, ligados ao movimento simbolista, que se reuniam no Café Paris: mais precisamente, os poetas Lima Campos, Mario Pederneiras e o crítico e romancista Gonzaga Duque. Eles já haviam fundado a revista Pierrot em 1890 e, posteriormente, em 1907, foram responsáveis pelo lançamento da Fon-Fon! (Oliveira et al., 2010).

Nesse contexto, destaca-se a atuação do ilustrador Julião Machado, que trazia o espírito da belle époque em suas produções, após ter trabalhado em Portugal e Paris e ter tido acesso aos avanços da tecnologia gráfica da época, principalmente em relação à construção de imagens. Assim, mesmo antes do período da grande reforma urbana do Rio de Janeiro, pode-se considerar a produção de Julião Machado como parte de um momento propulsor da belle époque carioca. Sua produção nas revistas A Cigarra (1895-1896), A Bruxa (1896-1897) e O Mercúrio (1898) refletem o espírito desse tempo e a modernidade do traço e das imagens construídas por meio de uma mistura de técnicas litográficas. A estética dessas ilustrações diferia da produção cinzenta do crayon litográfico que predominou na imprensa brasileira durante todo o século XIX. Somado a isso, pode-se perceber a clara influência do estilo art nouveau em algumas de suas produções, o que deixa patente sua atualização estilística em relação ao que ocorria em Paris, expoente da belle époque na época (Fonseca, 2016b).

A revista $O$ Mercúrio tinha na publicidade sua razão de existir e este artigo pretende apresentar as estratégias comerciais e os anúncios veiculados nesse periódico que se espelhava nas publicações parisienses de cartazes e inovou ao redimensionar o conteúdo publicitário em suas páginas e incluir a impressão dos reclames em duas cores.

A pesquisa se insere no campo de estudos da memória gráfica brasileira e sua abordagem está relacionada à configuração do conteúdo editorial e publicitário na revista, que pretendia atender aos anseios dos leitores que vivenciavam os impactos da modernidade. O estudo dessas estratégias comerciais e informacionais fazem parte do escopo do design na informação na medida em que se define por planejamento e configuração de uma mensagem em determinado meio, visando satisfazer as necessidades informacionais dos destinatários (SBDI, 2020). 


\section{Metodologia}

A pesquisa para este artigo utilizou o Conjunto Metodológico para Pesquisa em História do Design a partir de Materiais Impressos (Fonseca et al., 2016a) na condução da identificação e mapeamento dos acervos consultados, na organização do acervo digital produzido, na coleta de dados e tabulação digital, a fim de viabilizar as análises das variáveis e as possíveis interpretações e comparações.

A investigação foi fundamentada por revisão bibliográfica especializada para dar subsídios a respeito do contexto histórico, da tecnologia gráfica e da imprensa ilustrada brasileira no século XIX, e, em consultas à fonte primária (Oliveira et al, 2010; Süssekind, 1987; Martins, 2008; Lima, 1963; Fonseca, 2016b; Sevcenko, 1998). Obteve-se acesso aos exemplares d'O Mercúrio por meio do acervo físico da Fundação Casa de Rui Barbosa, onde foi possível fotografar as revistas e obter imagens em cores, e, também, a partir de consultas à Hemeroteca Digital da Biblioteca Nacional, que disponibiliza páginas de periódicos em alta resolução, permitindo leitura e aferição de detalhes, em preto e branco.

Foi realizada análise da revista O Mercúrio, sendo a mesma utilizada como objeto e fonte de pesquisa. Além dos anúncios identificados e analisados, foram utilizados também os textos publicados em suas páginas para a compreensão de seu propósito editorial e comercial.

\section{Apresentação editorial e gráfica da revista $O$ Mercúrio}

O espaço do conteúdo comercial n'O Mercúrio foi ditado pela nascente, mas agressiva, onda publicitária e pela importante relação entre as revistas ilustradas da belle époque brasileira com a nascente cultura da modernidade na "capital irradiante" (Sevcenko, 1998).

A revista era de propriedade de Gaston \& Alves, foi lançada em junho de 1898, no Rio de Janeiro e custava 200 réis. No cabeçalho da edição inaugural, informou que era impressa na litografia de Paulo Robin \& Pinho e anunciou que pretendia ser um "magazine" voltado "para o comércio, indústria e artes". Ademais, afirmou que nascia com um interesse maior do que apenas lucrar com a exploração publicitária, que seria de difundir "o cartaz artístico pelo único processo compatível com o seu particular modo de ver e satisfazer as necessidades da sua vida comercial" (O Mercúrio, n. 1, p. 2, 1898). Esse editorial corrobora com a afirmação de Herman Lima (1963) de que a revista divulgava no Brasil a moda da imprensa de Paris e seus cartazes art nouveau.

Ainda no editorial da primeira edição, dissertou sobre o Rio de Janeiro, como um dos mais importantes polos comerciais do país e, que por motivos desconhecidos, a propaganda ainda estaria restrita a uma rotina que não condizia com aquele tempo. Além disso, criticou o alcance dos anúncios de jornais, que não possuíam destaque nas páginas, e, também, os anúncios publicados nos almanaques, dizendo que serviam apenas à vaidade do anunciante e ficavam esquecidos no fundo das escrivaninhas. Tudo isso para valorizar o novo e moderno produto ofertado pela revista, que tinha como modelo as publicações congêneres europeias ( $O$ Mercúrio, n.1, p.2, 1898): 
Sobre esta grande vantagem terá o anunciante a de possuir um belo cartaz mural (affiche), bastando para tanto, destacar da Revista a parte que Ihe diz respeito.

E é neste ponto que julgamos prestar serviços aos comerciantes e industriais do Brasil.

O cartaz mural constitui, hoje em dia, o mais preferível gênero de anúncio em toda a Europa e

América (O Mercúrio, n.1, p.2, 1898).

A apresentação da revista e seu produto publicitário deixa clara a busca por uma comunicação moderna com os cartazes artísticos, chamados por ela mesma de affiches, fazendo referência à produção francesa, expoente da belle époque. Isso fica patente pois, além do texto supracitado, a capa da edição inaugural apresenta uma famosa propaganda cromolitogravada dos papeis de fumo Job, com a seguinte legenda: "Reprodução livre de um cartaz de Cheret, impresso em Paris, em grande formato" (O Mercúrio, n.1, capa, 1898). Um claro indício da referência art nouveau e da busca pela configuração moderna dos anúncios publicitários (figura 1).

Figura 1: Capa da edição inaugural com reprodução do famoso anúncio de papel de fumo Job. $O$ Mercúrio, nº 1, jun/1898. Fonte: Acervo digital da Fundação Biblioteca Nacional - Brasil.

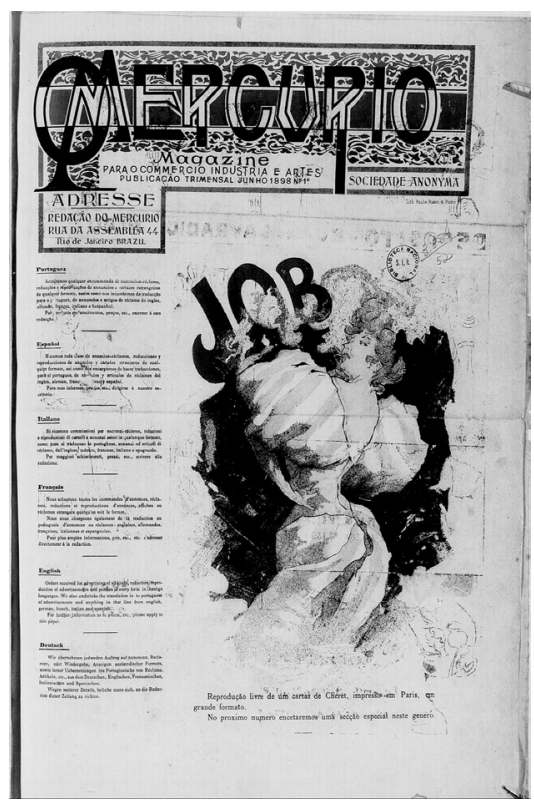

Nessa emblemática capa, anunciou que aceitava qualquer encomenda de "anúnciosreclame, reduções e reproduções de anúncios e cartazes estrangeiros de qualquer formato, assim como nos incumbimos da tradução para o português, de anúncios e artigos de reclame do inglês, alemão, francês, italiano e espanhol" (O Mercúrio, n.1, capa, 1898).

Vale lembrar que outras revistas veiculadas na segunda metade do século XIX já haviam incluído um suplemento comercial, a diferença é que a publicidade n'O Mercúrio era sua razão de existir, e as propagandas se integravam à edição e ao conteúdo editorial. Em meio às colunas de texto, eram publicadas notas que pretendiam convocar novos clientes para seus anúncios comerciais, tais como: 
Fazer um anúncio ilustrado e colorido no Mercúrio é tê-lo em todas as paredes, em todas as coleções, em todas as casas.

Saber anunciar é tudo, e isso o "Mercúrio" sabe fazer.

Um comerciante que não anuncia, só pode ter lucros mesquinhos.

Os melhores e mais bem feitos anúncios são os do Mercúrio.

O Mercúrio - como diz o seu título - é um diário destinado ao anúncio-reclame, que é o melhor dos anúncios.

O anúncio ilustrado e colorido encanta a vista, desperta a curiosidade e obtém bons resultados.

Se quereis um bom anúncio procure O Mercúrio (O Mercúrio, n. 9, 1898; n. 16, 1898; n.18, 1898 e n. 19, 1898.

Essas chamadas com o intuito de vender espaço publicitário em suas páginas destacam a possibilidade de produção de anúncios coloridos e colecionáveis que poderia encantar, despertar curiosidade e estar nas paredes das casas dos leitores.

O conteúdo editorial se dividia entre seções corriqueiras ou diárias, como Expediente, Diversão de Serão, O Azar e Sport; e diversas seções esporádicas ou semanais, como por exemplo: Theatros, Notas Mundanas, Chronica da elegância, A moda dos Chapéos no século $X I X$, Folhetim, e Os nossos industriaes, seção anunciada desde o início da publicação, prometia apresentar os mais importantes estabelecimentos fabris da capital e a biografia de seus fundadores e diretores, ou seja, aqueles que deveriam anunciar seus produtos na revista.

Quanto à periodicidade, foi lançada em junho de 1898 com o intuito de ser trimensal, porém na edição seguinte, em 19 de julho, já anunciava ser uma "publicação diária do magazine Mercúrio" (O Mercúrio, n.2, capa, 1898).

A publicação da revista foi destaque na imprensa brasileira por conta da colaboração de ilustradores como Julião Machado, Raul Pederneiras, Calixto Cordeiro e Arthur Lucas, que assinava Bambino. O impacto d'O Mercúrio se deveu, em grande parte, à sua apresentação gráfica, fruto da parceria de Julião Machado com os ilustradores supracitados que estavam iniciando suas carreiras.

Um dos grandes diferenciais da revista O Mercúrio foi seu acabamento feito apenas com dobras, sem refile e encadernação, das edições 2 a 43 . O espaço apresentado era similar às publicações contemporâneas, mas a revista era entregue aos leitores com duas dobras, uma no sentido vertical e outra na horizontal, o que permitia o uso do espaço para as imagens de forma contínua. $O$ formato de sua folha aberta era de $55 \mathrm{~cm}$ de largura por $76 \mathrm{~cm}$ de altura. A impressão da revista era litográfica, dando continuidade ao modo de produção empregado por Julião Machado em A Cigarra e A Bruxa, sendo um lado da folha impresso na cor preta, e, o outro lado sempre combinando o preto e uma segunda cor para complementar e preencher as ilustrações (figuras 2 e 3). A diferença de produção de cada lado da folha também determinava o tipo de conteúdo publicado, sendo o lado monocromático reservado para os textos, títulos ilustrados, charges e caricaturas a traço, e, o outro lado da folha reservado para as charges, caricaturas e anúncios em quadros maiores, que ocupava uma ou duas faces das dobras e 
sempre eram produzidos em duas cores. Ocorria de variar a segunda cor das ilustrações na produção de uma mesma edição, ficando cada metade da folha com uma segunda cor diferente.

Figura 2: Lado dedicado majoritariamente aos textos. O Mercúrio, n ${ }^{\circ}$, 22/07/1898.

Fonte: Acervo digital da Fundação Biblioteca Nacional - Brasil.

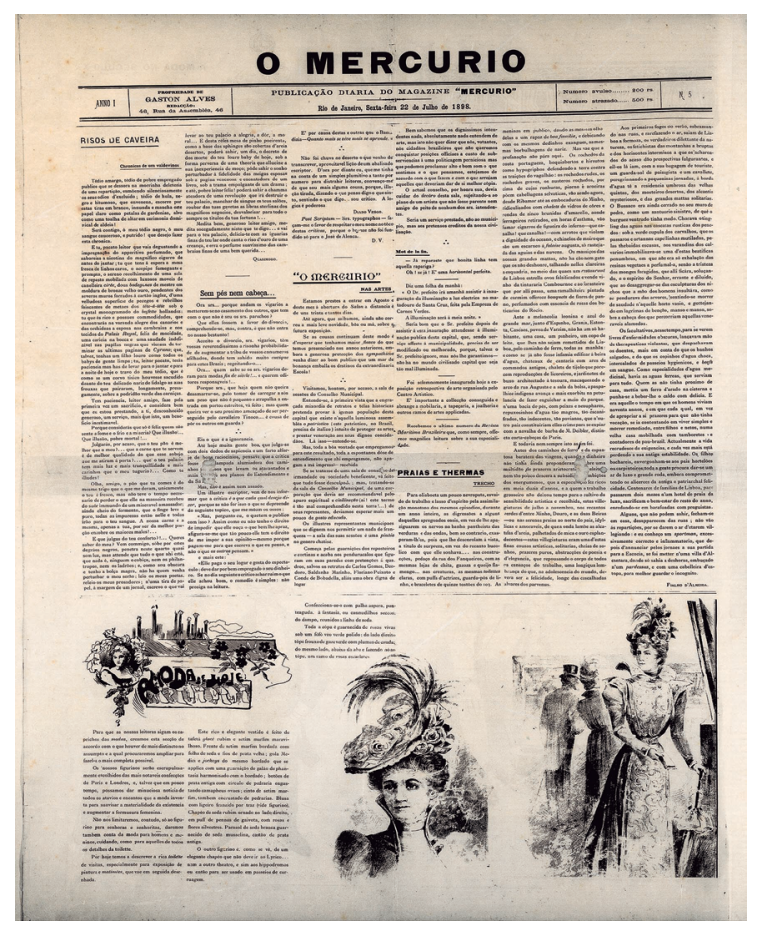

Figura 3: Lado dedicado às ilustrações. O Mercúrio, nº 39, 01/09/1898. Fonte: Acervo da Fundação Casa de Rui Barbosa.

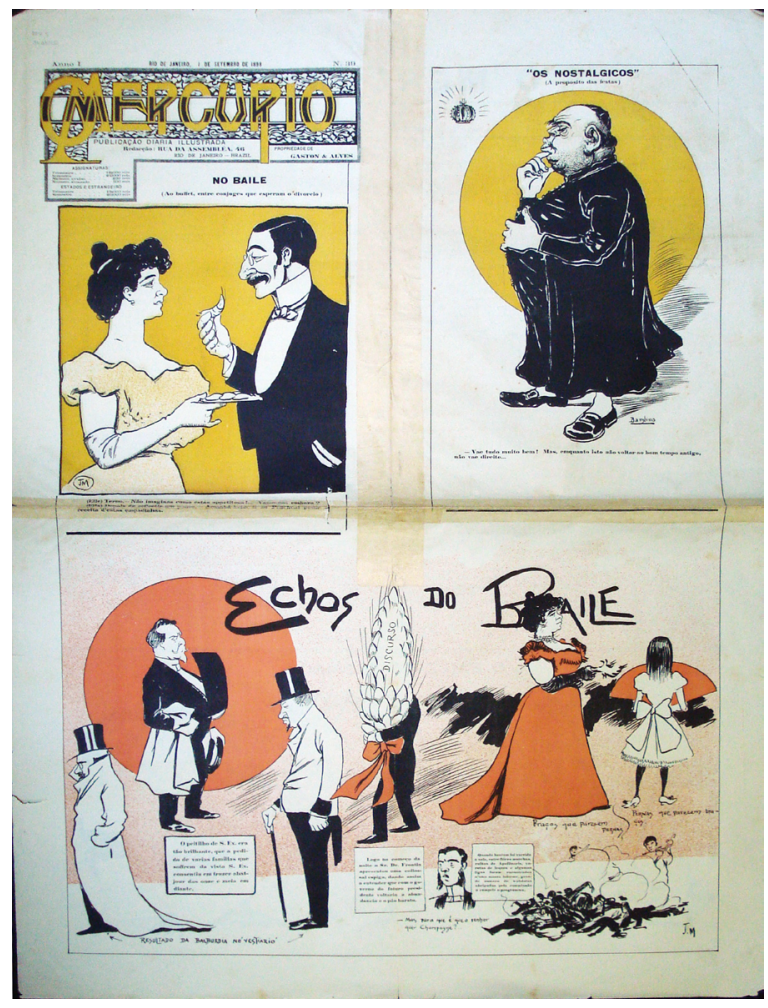




\section{Análise do conteúdo publicitário}

Nesse tópico serão apresentados os formatos dos anúncios identificados n'O Mercúrio e o panorama do conteúdo publicitário ao longo das edições da revista, que foi encerrada após 89 edições.

Já na terceira edição da revista, tem-se o primeiro anúncio ilustrado e em duas cores dividindo o espaço em um dos quadrantes do lado da folha destinada às charges e caricaturas. Tratava-se de um anúncio da Cerveja Teutonia, composto por um lettering com o nome do produto e uma cena com um personagem. $O$ anúncio foi construído a partir de diferentes técnicas litográficas, como traços a bico de pena, pinceladas e espargido ${ }^{1}$ (figura 4).

Figura 4: Revista aberta, lado das imagens. O Mercúrio, n³ 3, 20/07/1898. Fonte: Acervo da Fundação Casa de Rui Barbosa.

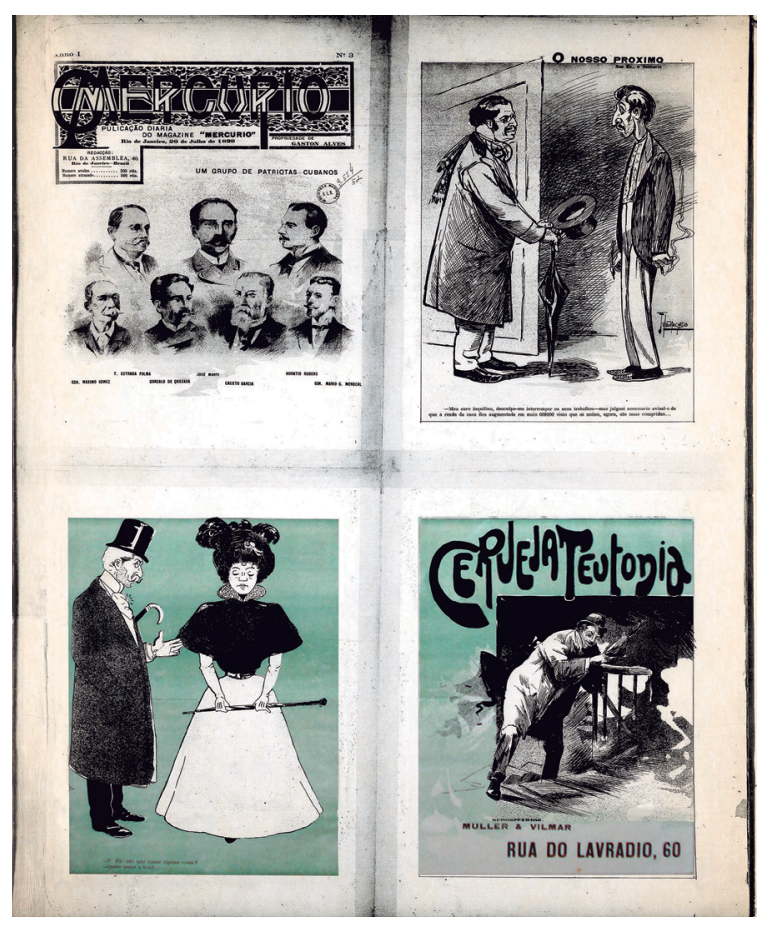

Outro anúncio digno de nota, por também ter sido apresentado em um quadrante exclusivo da folha e impresso em duas cores, reflete as novidades da vida moderna. A cena com as Bicyclettes Clevelland é composta por personagens elegantemente trajados e os dois homens em primeiro plano apresentam biotipos que deveriam atestar a eficiência dos dizeres do slogan: "são as mais velozes e resistentes" (figura 5) (O Mercúrio, n. 13, 1898).

\footnotetext{
${ }^{1}$ O espargido "consiste em borrifar a pedra com tinta, por meio de tela metálica e escova. Dependendo da distância da tela em relação à pedra, da quantidade de tinta empregada e do tamanho das gotículas de tinta aplicadas, o efeito final podia variar" (Fonseca, 2016b, p. 20).
} 
Figura 5. Anúncio das Bicyclettes Clevelland. O Mercúrio, nº 13, 01/08/1898. Fonte: Acervo da Fundação Casa de Rui Barbosa.

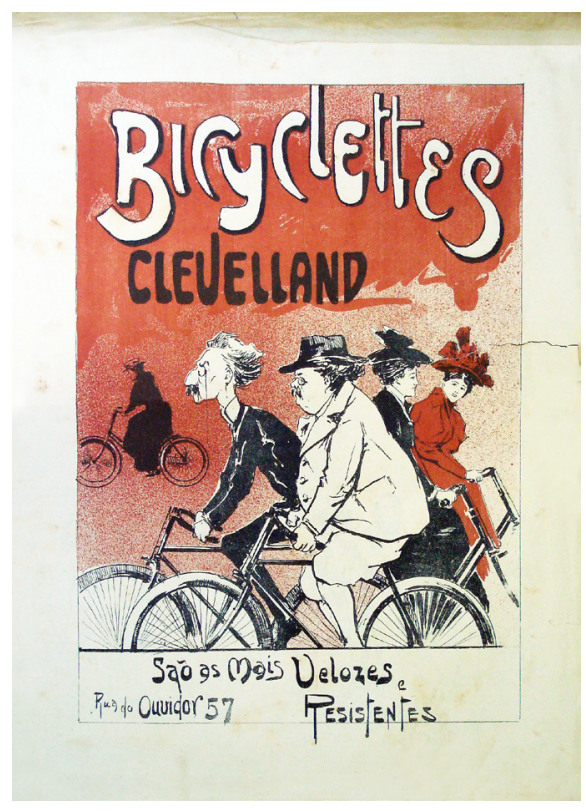

Apesar de todos os argumentos expostos pela própria publicação sobre a importância de anunciar por meio de cartazes murais e de noticiar insistentemente seus préstimos, a revista não obteve muitas encomendas e, na edição 13 , publicou um desabafo provocativo destinado aos comerciantes:

Exceção de alguns representantes do comércio desta capital, espíritos desenvolvidos em proveitosas viagens e cultivados por leituras de excelentes revistas estrangeiras, a maioria de seus honrados representantes não se dignou de atender ao que, com a precisa clareza, nos propusemos.

$[\ldots]$

Ora, tendo nós argumentado as vantagens que o anúncio ilustrado a cores, "em jornal inegavelmente baratíssimo (atentas as dificuldades do nosso meio artístico e o excessivo preço da mão de obra) trazia sobre os demais anúncios, tendo nós demonstrado o apuro que procuramos empregar na feitura da nossa folha dando um número prospecto a cinco cores _único no seu gênero, neste país"_e logo em seguida metendo ombros a um empreendimento que tem causado admiração aos que sabem o quanto custa um jornal ilustrado, como é este empreendimento de uma folha diária desenhada, esperávamos que a animação do comércio viesse recompensar nossos extraordinários esforços, por quanto lhe oferecíamos, de maneira que raras vezes se reproduzirá, "o mais moderno e o mais vantajoso sistema" de vulgarização de seus gêneros. [...]

Torna-se necessário que o comércio atenda ao que pretendemos e veja que, se o Mercúrio não oferecesse leitura variada e leve aos seus compradores, certo que o favor público não viriam em nosso auxílio nem, tampouco, o anúncio teria eficácia. (O Mercúrio, n. 13, 1898).

A publicação supracitada faz uma provocação ao iniciar dizendo que poucos comerciantes possuíam bagagem cultural oportunizada por viagens e leituras de revistas estrangeiras, já que a maioria não havia entendido a grande oportunidade que seria publicar um anúncio-cartaz a cores, fruto de esforços extraordinários. 


\section{Os anúncios ilustrados produzidos em cores}

Analisando as edições da revista nos acervos consultados na Casa de Rui Barbosa e na Hemeroteca Digital da Biblioteca Nacional, temos inserções de anúncios coloridos de página inteira, publicados junto às charges e caricaturas em apenas 5 edições $(3,4,13,63$ e 66), sendo as duas últimas reproduções reduzidas dos dois únicos cartazes anúncios contratados ao longo de sua trajetória. Infelizmente esses cartazes, produzidos em 5 cores, não constam junto ao acervo da revista, sua existência foi amplamente comentada em suas páginas e eles foram publicados em formato reduzido e em apenas duas cores nas páginas da revista.

O primeiro cartaz-anúncio contratado foi divulgado junto ao número 54 e amplamente noticiado nas edições seguintes, com reprodução reduzida publicada na edição 66 (figura 6)

Figura 6: Anúncio publicitário para a Cerveja Teutonia é uma reprodução reduzida do cartaz realizado para a empresa. O Mercúrio, nº 66, 05/10/1898, p. 8.

Fonte: Acervo digital da Fundação Biblioteca Nacional - Brasil.

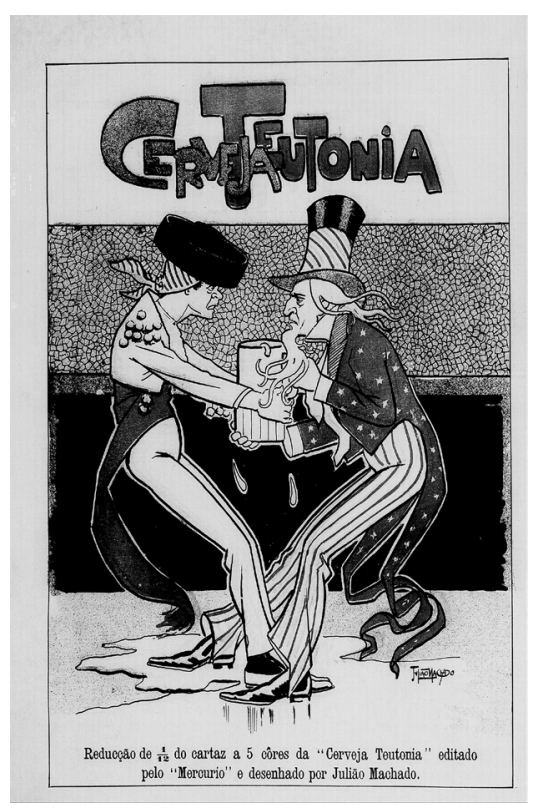

O enorme cartaz-artístico encomendado pela cerveja Teutonia foi digno de nota em diversos jornais, tais como: Jornal do Comércio, Gazeta de Notícias, O Debate, Jornal do Brasil, A Notícia, Cidade do Rio, A Ronda e A Tribuna (O Mercúrio, n. 61 e 62, p.2, 1898). E a revista fez questão de transcrever todos os comentários nas edições 61 e 62 , atestando seu estrondoso sucesso.

E o atraente Jornal do Brasil, que n'esta terra representa a atividade yankee da imprensa, noticiou: < Como suplemento ao seu número de ontem, apresentou o Mercúrio aos seus inúmeros leitores um excelente cartaz a cores da cerveja Teutonia, magnífico trabalho do artista Julião Machado. O esplêndido cartaz é digno da casa que o mandou fazer, do artista que o executou e das oficinas em que foi impresso.>> (O Mercúrio, n. 61, p.2, 1898).

A Tribuna, [...] noticiou: 
$<<[.$.$] Impresso a cinco cores e bem desenhado, é incontestavelmente este um dos mais completos e$ difíceis trabalhos que temos visto, dos feitos aqui.>> Tribuna (O Mercúrio, n. 62, p.2, 1898).

E ainda deu publicidade aos telegramas supostamente recebidos de Cheret e Mac-Linley, deixando claro que se não foi pessoa de outro nome ou confusão do telegrafista, eram os renomados artistas de cartazes publicitários da época.

A revista continuou utilizando o sucesso do cartaz publicado para destacar a importância dessa abordagem publicitária, destacando o inspirado lápis de Julião Machado, discípulo de Cormon, ateliê onde estudou em Paris e que já havia sido frequentado por Van Gogh e Toulouse Lautrec. Relembra os elogios da imprensa, as rodas populares extasiadas diante dos muros em que figuram os cartazes e reafirmava que nunca houvera anúncio tão sensacional, tão verdadeiramente anúncio-reclame no Rio de Janeiro. E exalta o "gênio empreendedor" dos Srs. Muller \& Vilmar, proprietários da fábrica da Cerveja Teutonia, afirmando que eles "compreendem que fazer comércio lucrativo não é regatear um anunciozinho de dez linhas, apertado entre milhares de baboseiras, numa coluna pesada de jornal". E atribui ao anúncio moderno o fato da referida cerveja ser supostamente a predileta do público em pouco tempo $(O$ Mercúrio, n. 66, p. 7, 1898).

O público tem muito que fazer, as suas ocupações são exigentes, os seus deveres absorvem-Ihe a atenção. Para que ele atenda a uma especialidade fora da esfera dos seus cuidados, para que ele delibere experimentá-la, é necessário que se o arranque das suas importantes meditações, que se o impressione na absorção em que vive.

$[\ldots]$ Nota bem o resultado deste cartaz.

A vida das suas figuras, a variedade das suas cores, o inexcedível acabamento do seu desenho, a graça da sua composição artística chamam logo a atenção do transeunte. O primeiro que a vista depara prende-o. Há nele uma aplicação curiosa, uma febre de saber o que é, o que diz, o que representa. Vem o segundo cartaz e ele nota melhor, vem o terceiro e ele atende-o, lê os dizeres. Daí não mais Ihe sai da atentiva esta composição, e todas as vezes que dela se lembra vem-Ihe à memória os dizeres que estavam na página. Está conseguida a vitória! [...](O Mercúrio, n. 66, p. 7, 1898).

A segunda e última publicação de cartaz-anúncio foi para o Matte Laranjeira, anunciado e reproduzido nas páginas da edição 63 (figura 7), distribuído junto a edição 66 e comentado na edição 71. O título anuncia que é o segundo cartaz e que o sucesso continua. Mais uma vez, publicou as notas de outros periódicos sobre o feito. A seguir serão transcritos os comentários publicados pela $A$ Ronda:

$<<$ O Mercúrio, o nosso ilustradíssimo colega, distribuiu com o seu n. 66 , um belo anúncio-cartaz do excelente Matte Larangeira, a saborosa bebida nacional.

Julião Machado provou, mais uma vez, o mérito do seu lápis invejável.

O comércio desta capital e dos Estados não precisa mais fazer encomendas desses anúncios chics que nos embasbacavam, agora tem $O$ Mercúrio, que dispõe de elementos para satisfazer aos mais exigentes>> (O Mercúrio, n. 71, p. 2, 1898). 
Figura 7: Anúncio publicitário do Matte Laranjeira é uma reprodução reduzida do cartaz colorido que foi distribuído três dias depois junto à revista. O Mercúrio, n 63, 01/10/1898, p. 8. Fonte: Acervo digital da Fundação Biblioteca Nacional - Brasil.

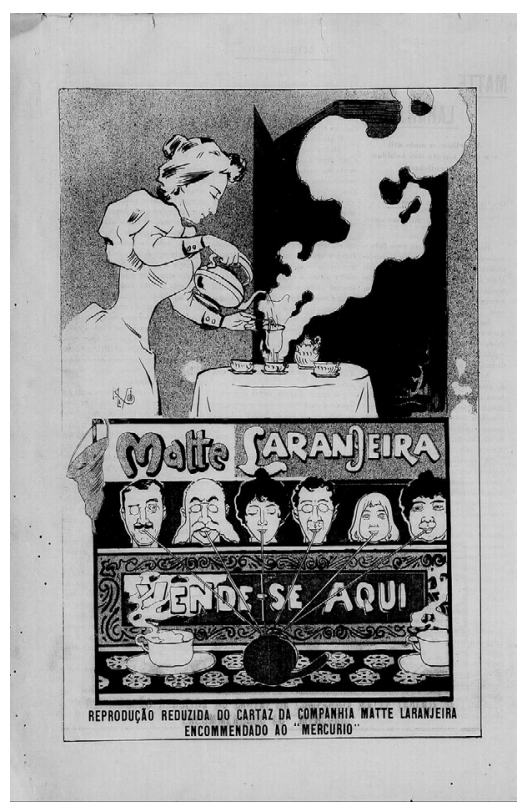

Apesar do sucesso comemorado, só foram observadas essas duas produções de anúncios cartazes nos registros do acervo estudado. Foi uma experiência importante, porém não se desenvolveu como era esperado no editorial de lançamento da revista.

\section{Os anúncios inseridos em meio ao conteúdo editorial}

Além dos anúncios em cores apresentados, observou-se a inserção de conteúdo publicitário dividindo espaço e se valendo do conteúdo textual da publicação (figura 8). Foi o caso de um anúncio da Cerveja Teutonia, que uniu título ilustrado com cena e um extenso texto apresentando a cerveja, sua composição, sua fábrica e sua atuação no mercado. Para a parte imagética se valeu da cena de um suposto bar ou restaurante frequentado por diversos homens bem-vestidos e usando cartolas, o perfil dos consumidores almejados pela empresa. Além disso, o título foi desenhado e posicionado com cada palavra em uma extremidade da imagem com sobreposição de alguns elementos.

Figura 8: Anúncio publicado no rodapé da página de textos. O Mercúrio, n 12, 30/07/1898. Fonte: Acervo digital da Fundação Biblioteca Nacional - Brasil.

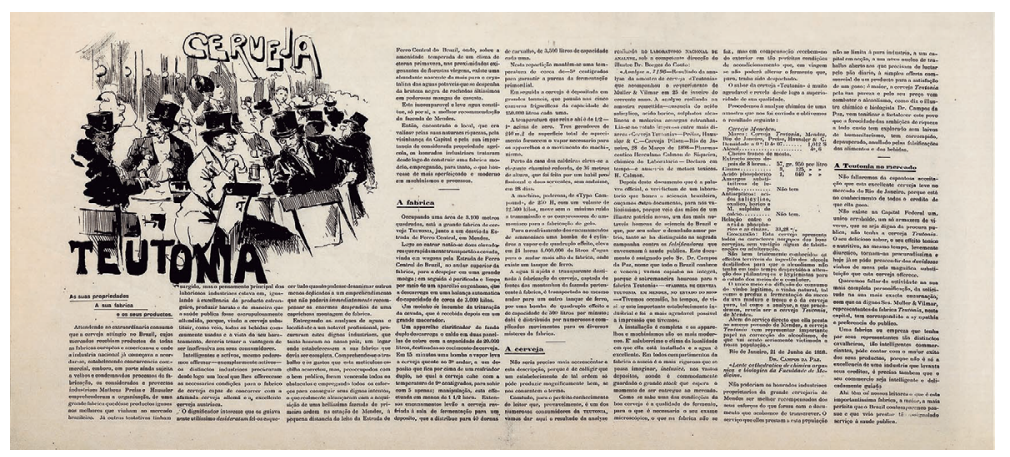


Além dos exemplos supracitados, outros formatos de anúncios foram identificados, como os ilustrados e divididos por quadros (figura 9); os inseridos nas margens das páginas de ilustrações (figura 10); os configurados como classificados, ocupando uma coluna da página de texto (figura 11); os ilustrados inseridos no meio da página de texto (figura 12); e por fim, os anúncios diversos divididos por fios na base da página de texto (figura 13).

Figura 9: Página de anúncios em quadros. O Mercúrio, n 1, jun/1898, p. 5. Fonte: Acervo digital da Fundação Biblioteca Nacional - Brasil.

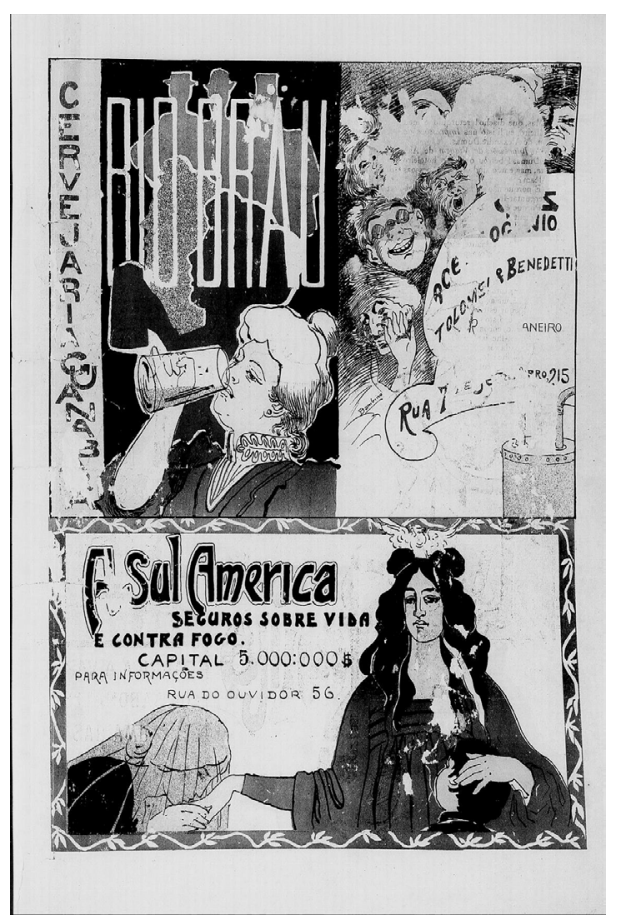

Figura 10: Anúncio da Água Inglesa de Freira Aguiar inserido na margem da página de ilustrações da publicação. O Mercúrio, nº 74, 13/10/1898. Fonte: Acervo da Fundação Casa de Rui Barbosa.

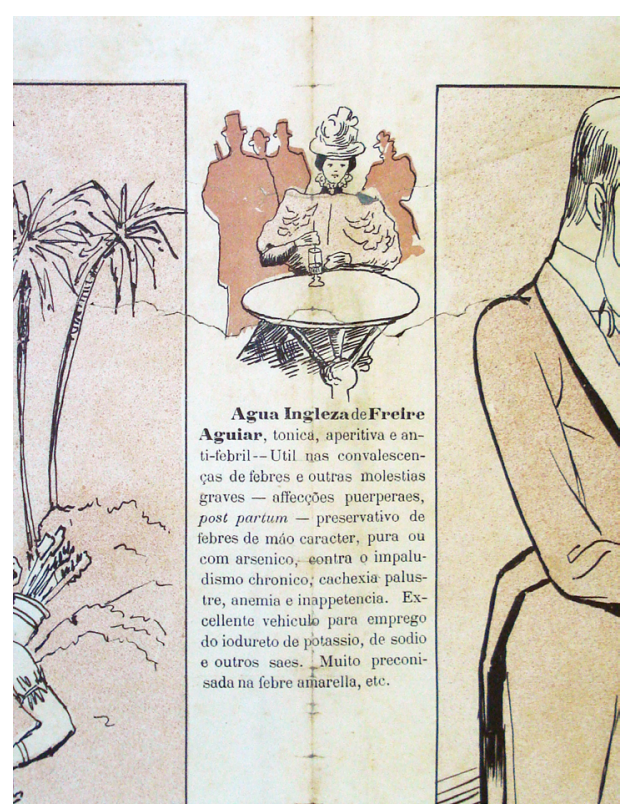


Figura 11: Anúncios configurados como classificados. O Mercúrio, nº 75, 14/10/1898, p. 3. Fonte: Acervo digital da Fundação Biblioteca Nacional - Brasil.

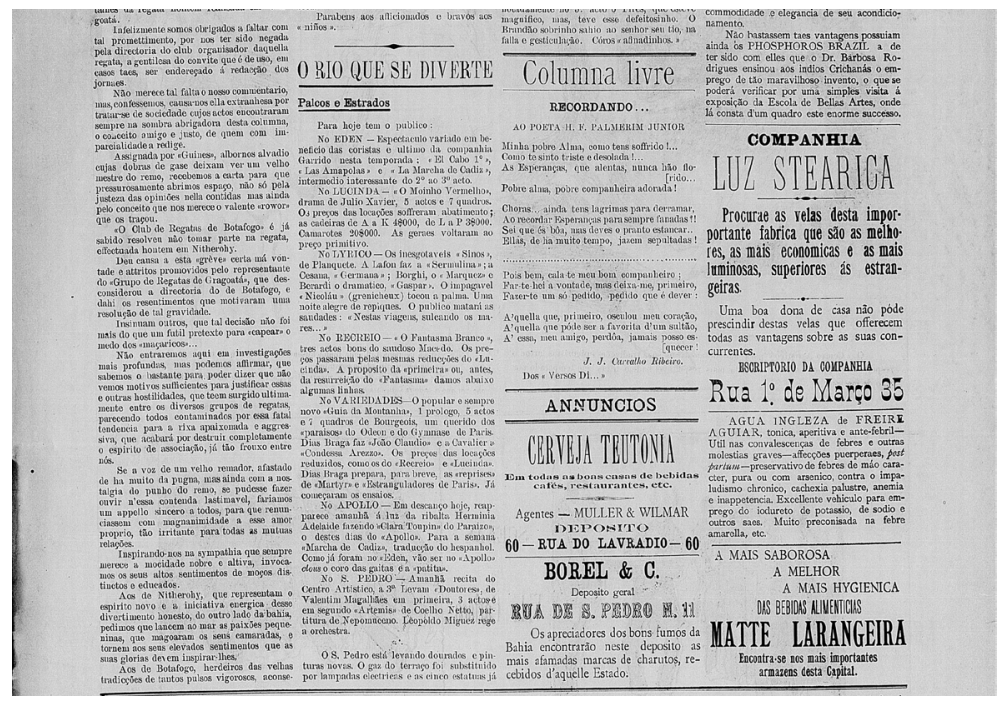

Figura 12: Anúncio inserido em meio à página dedicada ao conteúdo textual. O Mercúrio, $\mathrm{n}^{\circ} 81$, 20/10/1898, p. 3. Fonte: Acervo digital da Fundação Biblioteca Nacional - Brasil.

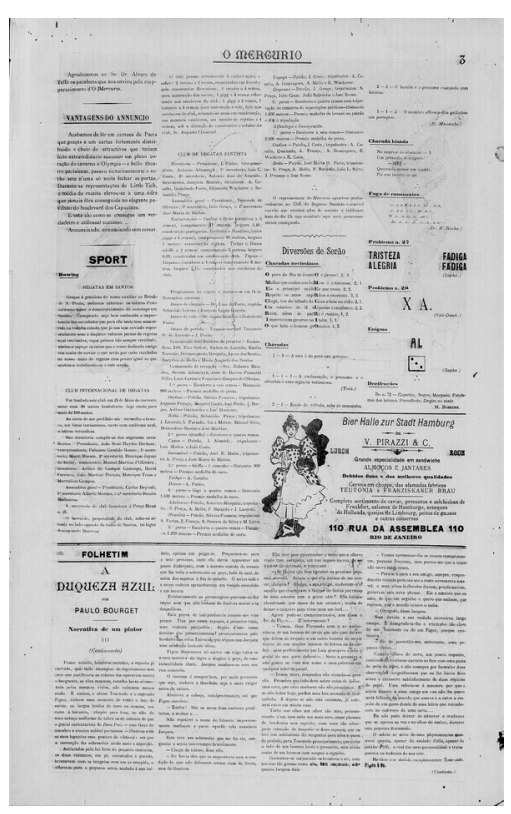

Figura 13: Anúncios diversos divididos por fios e dispostos na base da página destinada ao conteúdo textual. O Mercúrio, nº 18, 6/8/1898. Fonte: Acervo digital da Fundação Biblioteca Nacional - Brasil.

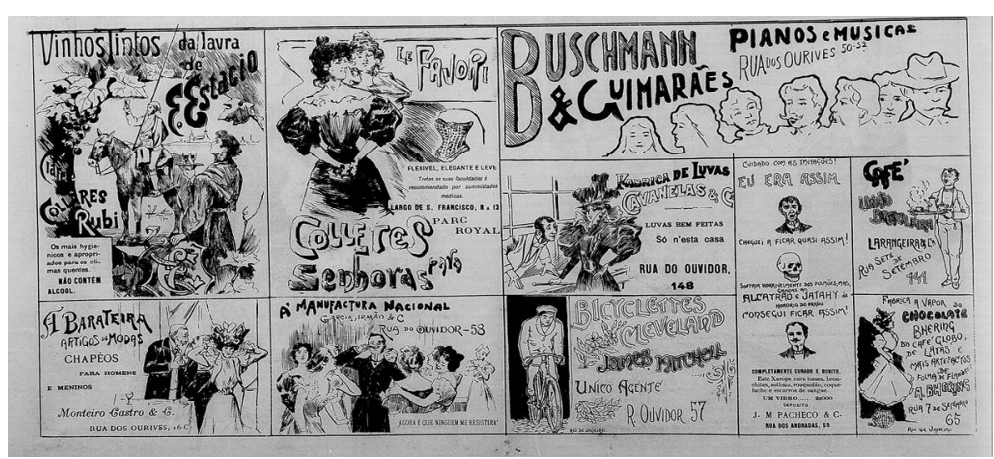


Com o objetivo de compreender a recorrência de uso dos diferentes espaços ocupados pelos anúncios ao longo das publicações, foi elaborada uma tabela para indicar as edições e quantificar as ocorrências. (tabela 1 ).

Tabela 1: Localização dos anúncios nas páginas, registro do número e da quantidade de edições.

\begin{tabular}{|c|c|c|}
\hline Localização dos anúncios & Número da edição & $\begin{array}{l}\text { Quantidade } \\
\text { de edições }\end{array}$ \\
\hline $\begin{array}{l}\text { Página inteira no lado dedicado } \\
\text { às ilustrações }\end{array}$ & $3,4,13,63,66$ & 5 \\
\hline $\begin{array}{l}\text { Diversos anúncios divididos por } \\
\text { fios em uma página }\end{array}$ & 1 & 1 \\
\hline Rodapé da página de texto & $2,12,17,18$ & 4 \\
\hline $\begin{array}{l}\text { Margens das páginas de } \\
\text { ilustrações }\end{array}$ & $\begin{array}{l}53,56,58,60,62,63,66 \\
68,69,70,72,73,74\end{array}$ & 13 \\
\hline $\begin{array}{l}\text { Inseridos no meio páginas de } \\
\text { textos }\end{array}$ & 80,81 & 2 \\
\hline Configuração de classificados & $75,76,77$ & 3 \\
\hline $\begin{array}{l}\text { Diversos anúncios divididos por } \\
\text { fios na base de uma página de } \\
\text { texto }\end{array}$ & $\begin{array}{l}82,83,84,85,86,87,88 \\
89\end{array}$ & 8 \\
\hline Nenhum & 19 a 52 & 34 \\
\hline
\end{tabular}

Constata-se que o projeto de publicação de cartazes-anúncios não foi bem sucedido e forçou a revista a apresentar anúncios no estilo que condenou em sua edição inaugural, tais como os classificados. Observou-se também que a revista que tinha na publicidade sua razão de existir não publicou nenhum anúncio entre as edições 19 e 52, ou seja, por mais de um mês de números diários.

Nos textos, em que publicava informações sobre ela mesma, havia um discurso de que o conteúdo era leve, variado e preparado para o novo estilo de vida das pessoas, que não tinham tempo para longas leituras. A partir da edição 74 , mudou de posicionamento editorial, anunciou que passaria a ser uma folha noticiosa e, na edição seguinte, já constava no cabeçalho a mudança de propriedade da revista para Fernando Adamczyk e companhia. Nas primeiras edições se desculpou com os leitores por não estarem atendendo à nova linha editorial a contento, pois não conseguiram publicar as notícias do telégrafo, por exemplo. A nota publicada justifica o atraso por conta do tempo de produção de sua impressão litográfica e a agilidade necessária por conta das notícias telegráficas.

Após essa mudança editorial da revista, que já deveria ser reflexo de dificuldades, só se tem notícias da publicação até a edição de número 89 . Sendo que na edição 80 , foi publicada uma nota d'A Ronda celebrando o reaparecimento da revista O Mercúrio, que havia ficado 19 dias fora de circulação entre os números 77 e 78 . 


\section{Considerações finais}

Após a apresentação dos anúncios produzidos por Julião Machado para a revista O Mercúrio (1898), pode-se afirmar que foi uma produção ligada aos valores da belle époque, com foco no movimento art nouveau e em uma comunicação que se pretendia moderna.

As imagens litografadas com técnicas diferentes e sobrepostas produziam desenhos a traço e preenchimentos variados. A construção das propagandas valorizava cenas compostas pela elite, incluindo vestimentas e modos de se portar. O lançamento de novos produtos precisava do amparo da publicidade para se estabelecer e ganhar novos mercados.

N'O Mercúrio, pretendia-se focar nos cartazes-anúncio, porém só tiveram duas experiências de propagandas nesses moldes. Na revista ocorria a inserção da publicidade em meio ao conteúdo editorial e também o uso de páginas exclusivas. Pode-se perceber que a revista publicou poucos anúncios de página inteira e no final de sua trajetória concentrou anúncios diferentes no rodapé das páginas de texto, além de pequenos reclames inseridos nas margens no setor de ilustrações e no formato de classificados.

Pode-se considerar que a revista $O$ Mercúrio foi pioneira no propósito de ser suporte de anúncios publicitários por meio de cartazes e esse objetivo impactou seu projeto gráfico e seu acabamento, na medida em que grande parte das edições não eram refiladas e poderiam ser abertas de modo a apresentar uma folha inteira para abarcar os cartazes e se tornar um quadro para os leitores. Apesar do pouco tempo que ficou em circulação, seus textos editoriais registram dados preciosos que mostram o modelo dos cartazes parisienses em estilo art nouveau como ideal a ser seguido; além de sugerir que a nova mídia seria ideal para alcançar os atarefados leitores.

Por fim, acredita-se que suas edições inovadoras e os dois cartazes que produziu e divulgou amplamente, incluindo as reproduções reduzidas publicadas na própria revista, são um marco na história da imprensa e para os estudos da memória gráfica brasileira.

\section{Referências}

Fonseca, L. P.; Gomes, D. D.; Campos, A. P. (2016a). Conjunto Metodológico para Pesquisa em História do Design a partir de Materiais Impressos. Revista Brasileira de Design da Informação, v. 13, n. 2, p. 143-161.

Fonseca, L. P. (2016b). Uma revolução gráfica: Julião Machado e as revistas ilustradas no Brasil, 1895-1898. São Paulo: Blucher.

Lima, H. (1963). História da caricatura no Brasil. Rio de Janeiro: Livraria José Olympio Editora.

Martins, A. L. (2008). Revistas em revista: imprensa e práticas culturais em tempos de República (1890-1922). São Paulo: Edusp.

O Mercúrio (1898), Rio de Janeiro, n.1, junho 1898.

O Mercúrio (1898), Rio de Janeiro, n.2, 19 julho 1898.

O Mercúrio (1898), Rio de Janeiro, n.13, 1 agosto 1898. 
O Mercúrio (1898), Rio de Janeiro, n.61, 29 setembro 1898.

O Mercúrio (1898), Rio de Janeiro, n.62, 30 setembro 1898.

O Mercúrio (1898), Rio de Janeiro, n.66, 5 outubro 1898.

O Mercúrio (1898), Rio de Janeiro, n.71, 10 outubro 1898.

Oliveira, C.; Velloso, M. P.; Lins, V. (2010). O moderno em revistas: representações do Rio de Janeiro de 1890 a 1930. Rio de Janeiro: Garamond.

Sevcenko, N. (org.) (1998). História da vida privada no Brasil: República: da belle époque à era do rádio. São Paulo: Companhia das Letras.

Sociedade Brasileira de Design da Informação (SBDI). Brasil, 2020. Disponível em: <http://www.sbdi.org.br/definicoes>. Acesso em: 18 jul. 2021.

Süssekind, F. (1987). Cinematógrafo de letras: literatura, técnica e modernização no Brasil. São Paulo: Companhia das Letras.

\section{Sobre a autora}

Letícia Pedruzzi Fonseca, Dra., Ufes, Brasil, <leticia.fonseca@ufes.br> 